\title{
A Depositional Model for the Oligocene Turbidites in the Roncador Field: First steps.
} Flavio Zaborne Oliver*, Antonio Fernando Menezes Freire, Wagner Moreira Lupinacci.

\author{
Universidade Federal Fluminense - UFF
}

Copyright 2019, SBGf - Sociedade Brasileira de Geofísica

This paper was prepared for presentation during the $16^{\text {th }}$ International Congress of the Brazilian Geophysical Society held in Rio de Janeiro, Brazil, 19-22 August 2019.

Contents of this paper were reviewed by the Technical Committee of the $16^{\text {th }}$ International Congress of the Brazilian Geophysical Society and do not necessarily represent any position of the SBGf, its officers or members. Electronic reproduction or storage of any part of this paper for commercial purposes without the written consent of the Brazilian Geophysical Society is prohibited.

\begin{abstract}
Roncador is a giant oil field located in Campos Basin in water depths ranging from 1500 to 2000 meters. The field was discovered in 1996 and stands out as the third largest post salt production field of the basin. The reservoirs are siliciclastic turbidites deposited during the Upper Cretaceous. This work describes some of the turbidite sandstone deposits situated above the lower Oligocene maximum flooding event known as "Blue Marker" in the Roncador field. A 3D PSDM seismic volume and 15 wells were used to describe the external geometry, seismic characteristics and deposition of these turbidites bodies, and a depositional model is proposed on the basis of the integration well-seismic data.
\end{abstract}

\section{Introduction}

In the Roncador oil field (Fig. 1) the main reservoirs are the Maastrichtian siliciclastic turbidites, and these reservoirs were well studied and described by many authors (Rangel et al., 2003, Suarez et al., 2004, Peres 1993). In one hand, there are rare published studies concerning to the Oligocene turbidites in the Roncador oil-field, probably because there is no economic oil accumulation discovered in this interval, until now. On the other hand, in oil-fields like Barracuda, Albacora and Marlim, those Oligocene turbidites are the main reservoirs, so it is extremely important to understand the depositional model, the external geometry and the seismic characteristics of this deposits in order to give more accuracy and robustness on E\&P projects.

Discovered in1996, Roncador field contains reserves of 9.2 billion bbl in place and total reserves of 2.6 billion BOE. The field average production in 2018 was approximately 240,000 barrels of oil per day and 40,000 barrels of oil equivalent (oil and natural gas) per day. According to reports of the Agência Nacional do Petróleo Gás Natural e Biocombustíveis (ANP), it is expected an increasing of the total remaining recoverable volume from 1 billion boe to more than 1.5 billion boe in the next years with use of new technologies to increase oil recovery (IOR) by the consortium that operate the field.

A shelf-fed turbidite system model was proposed by Peres, 1993. This model includes (a) deposition of large volumes of siliciclastic sediments during the buildup of a shelf-sand rich unit, which later constitutes the main source of sediments; (b) localized tectonic pulses that modify the outer shelf declivity and trigger the mass flows; and (c) a relative fall of sea level; which causes the subaqueous exposure of the shelf sediments to be reworked in a shallow high energy marine environment.

Salt movement had a great controlling effect on the depositional patterns of the turbidite sandstones from early Albian to Paleocene, forming depositional lows which favored the sedimentary deposition (Rangel et al., 2003).

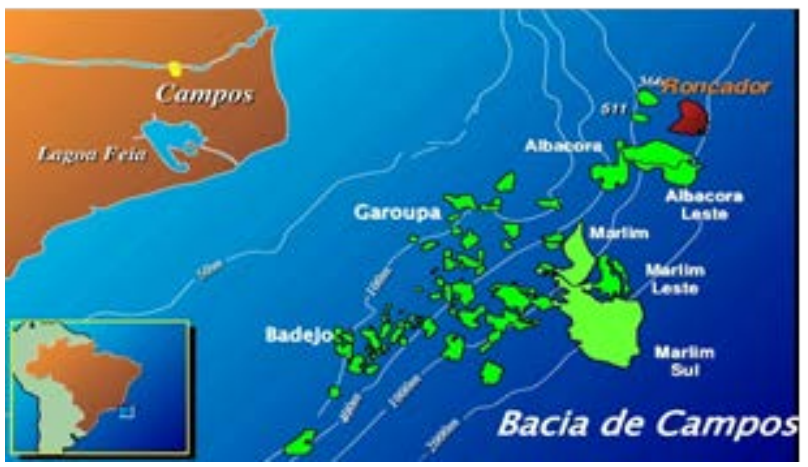

Figure 1: Highlighted in red is the Roncador field location in Campos Basin.

Analyzing the seismic data in the area it is easy to identify the salt diapirism that must have influenced the deposition of the turbidites bodies. Locally these deep-water sandstone turbidites are called Carapebus Formation.

A very important lower Oligocene event in the basin and highlighted in the area is the maximum flooding surface informally denominated "Blue Marker" (Winter et al. 2007). This surface is easily identified in the area being characterized by a strong high amplitude peak in the seismic sections and a carbonate layer in cores, lateral samples and cuttings, as well in well logs, where is observed a low gamma ray (GR) response in association to a high resistivity (RES) pick and to a lower transit time (DT). The Oligocene sandstone turbidites were deposited above the "Blue Marker" surface.

\section{Method}

A $200 \mathrm{~km}^{2}$ 3D PSDM seismic volume and 15 wells, gently provided by ANP, were used to describe the external geometry, seismic characteristics and deposition of Oligocene turbidites bodies in the area. The first step was to tie the wells to the seismic volume. The Blue Marker and the top of Carapebus formation were interpreted in all the wells using the log curves and the composite log, using the software Petrel version 2016 (Fig. 2). 


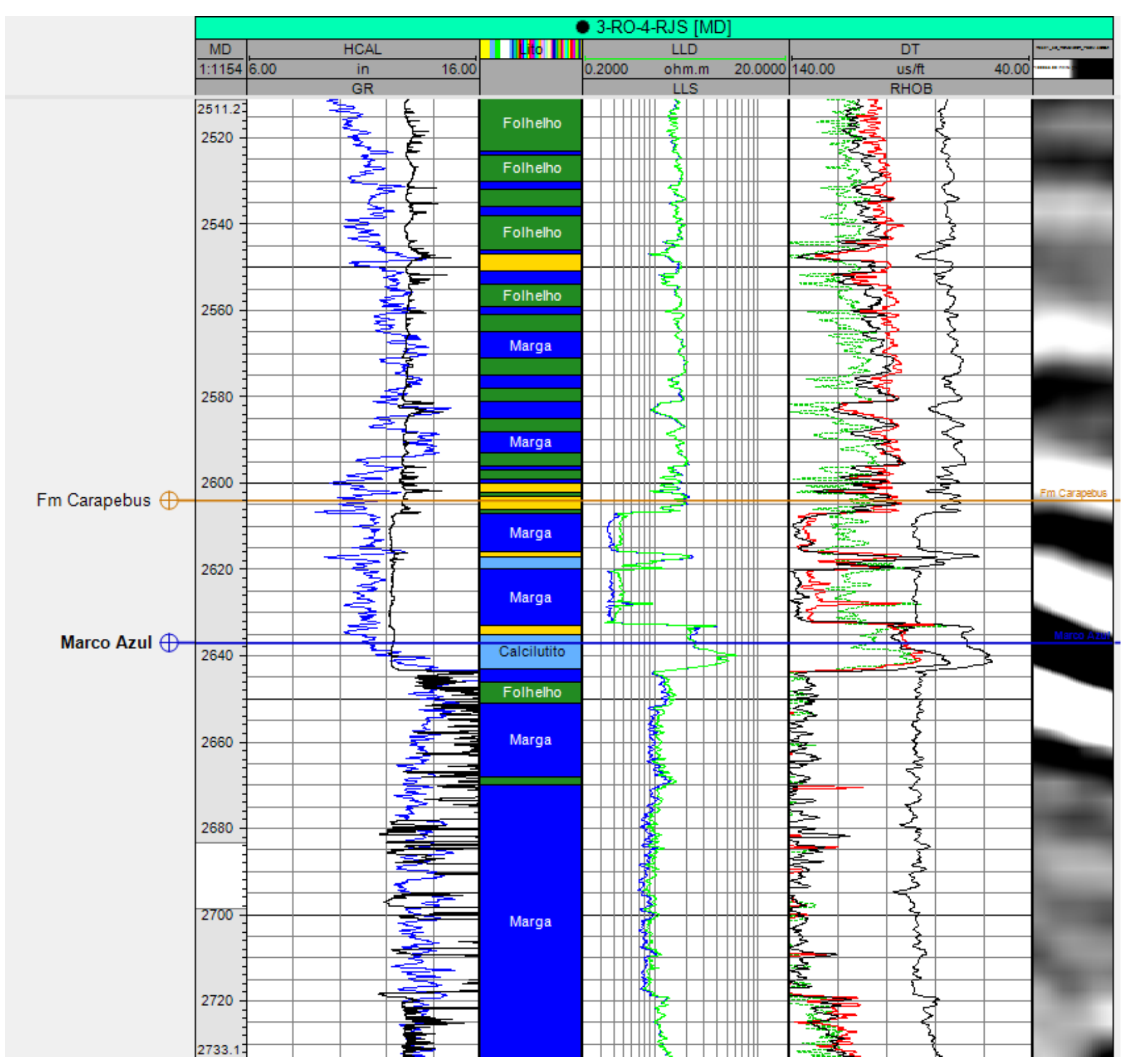

Figure 2: Blue Marker and Carapebus sandstone marker. The marker interpretation was based on gamma ray (GR), Resistivity deep and shallow (LLD-LLS), Density (RHOB), Neutron porosity (NPHI) and lower transit time (DT) well logs. The most left track shows the seismic log extracted from the seismic volume.

The interpretation of both Blue Marker and Carapebus sandstone horizons was done at every $10^{\text {th }}$ inline and $20^{\text {th }}$ crossline (Fig. 3).

After the interpretation, the horizons were gridded to a $50 \times 50$ meters mesh using the convergent algorithm. The next step was to generate the RMS (Root Mean Squares on instantaneous trace samples over a specified window) and the minimum amplitude seismic attributes of the resulting surfaces. The RMS and Minimum amplitude attribute computation were done on the seismic trace segments below the surface with a search window of 30 meters and from the closest peak event.

\section{Results and Discussion}

The interpretation of the Blue Marker horizon on the seismic sections shows continuity at the central part with a light plugging to SE direction. To the north of the area there is a pronounced erosional feature cutting the sequences and eroding even the Carapebus sandstones package deposited above (Fig. 4). The sedimentary section uplifted by halokinesis is the main result salt diapirism occurred in the basin. This salt movement is the principal factor for the tectono-depositional control on the sedimentary history above. 
This erosional feature seems to be essential for the delivery of sediments as canalized turbidite flows (Fig. 5). In this way, turbidite flows from the platform form turbidite fans that could be reworked by contourite currents, as proposed by Mutti et al. (2015). According to these authors, turbidity flows could be reworked as soon as they reached the base of the slope, being deposited in the preferred direction of the contour current, present in the depositional site, causing the resulting deposits to have an elongated shape in the direction of this current.

This study is now in an initial stage and the mapping of such elongate turbidite deposits is one of the targets.

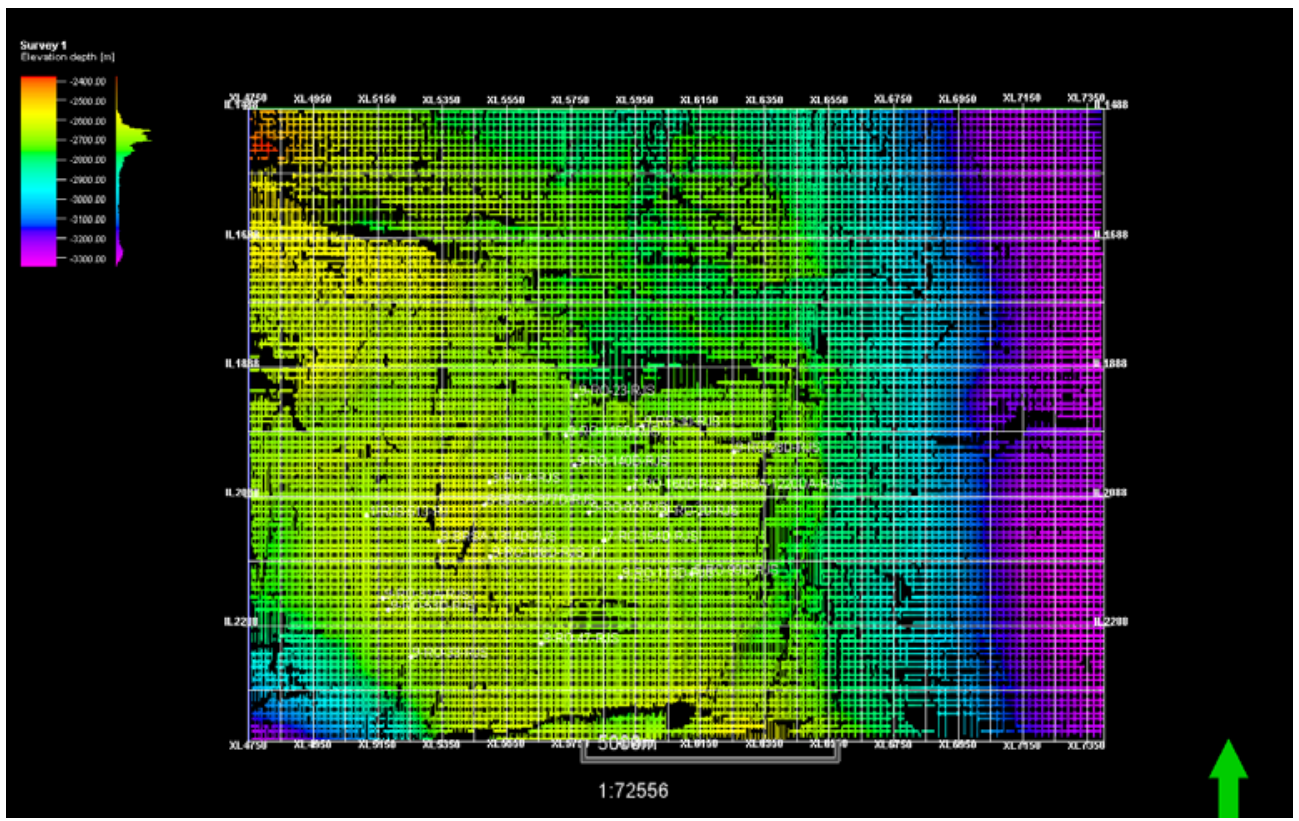

Figure 3: Blue Marker horizon interpretation from PSDM volume, done at every $10^{\text {th }}$ inline and $20^{\text {th }}$ crossline.

The thickness of Oligocene Carapebus sandstones mapped in the area range from 80 to 110 meters with the layers stratigraphically pinching out against the Blue Marker surface (Fig. 6). In the seismic inlines this sandstone package shows a typical turbidite external geometry (seagull's wing shape). The direction of turbidite current flux seems to have been from northwest to southeast as shown in the RMS attribute map (Figs. 7 and 8).

For the next steps, this study is planning to focus on the mapping of the external geometry for the construction of a depositional model to explain the Oligocene Carapebus deposition and, in a final point of view, to preview the best reservoir facies for a possible oil discovery.

\section{Conclusions}

This work, although very preliminary, shows interesting features of the Oligocene turbidites deposited in the Roncador oil field area. Seismic interpretation of the Blue Marker and Carapebus sandstone horizons show a strong erosive event that affected both formations in the northeast. This erosional feature seams to control the deposition of channelized turbidities sandstones. The RMS attribute map and top Carapebus sandstone surface shows a northwest to southeast direction of turbidite current flux.

\section{Acknowledgments}

The authors are grateful to ANP for providing the data for the research and Schlumberger for making PETREL software licenses available for academic use at the Universidade Federal Fluminense - UFF. 
A Depositional Model for the Oligocene Turbidites in the Roncador Field

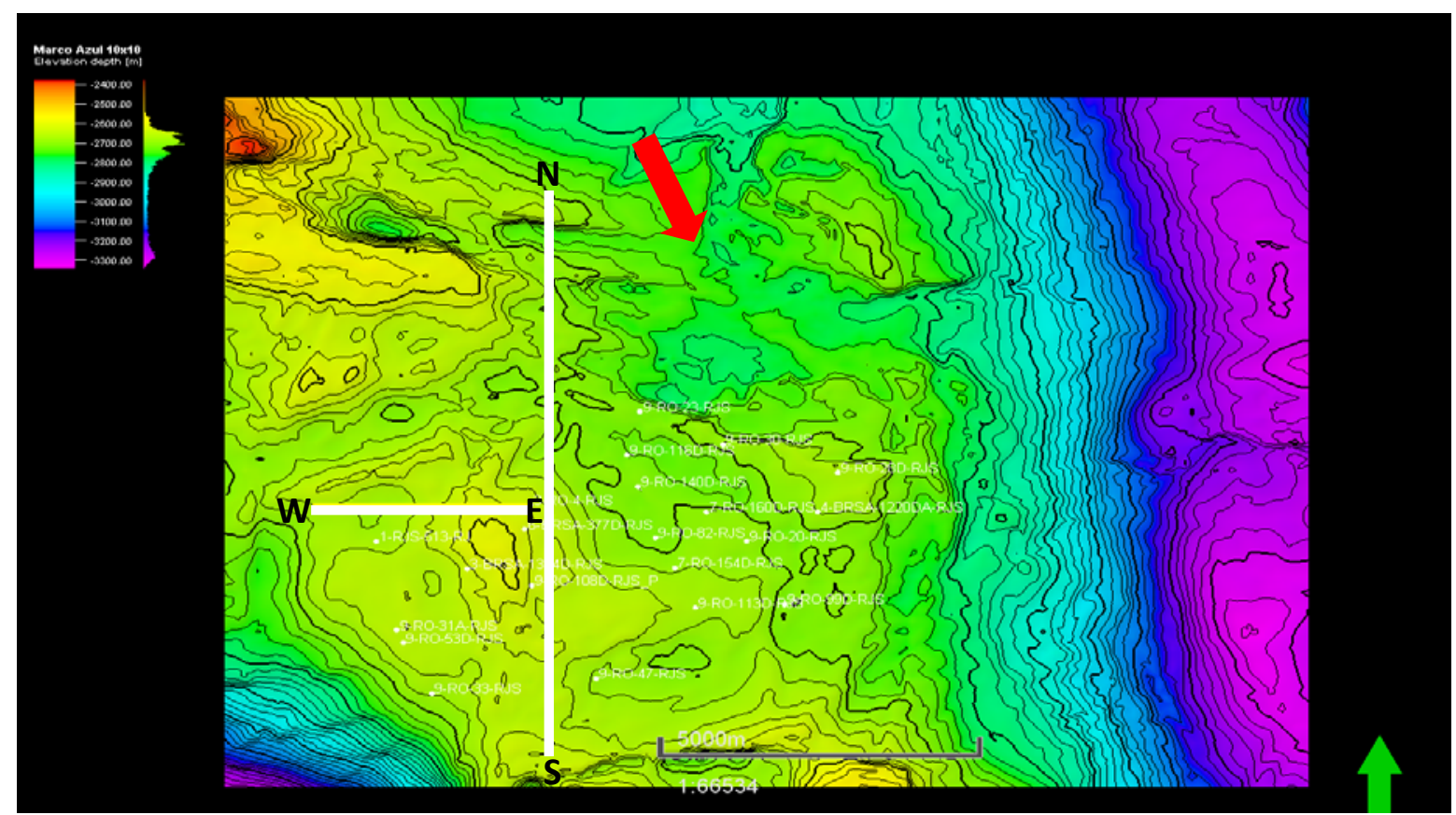

Figure 4: Blue Marker surface showing a pronounced erosive feature (red arrow) in the area. Color bar shows $Z$ values from -2400 (red) to -3300 (purple) meters. In white the N-S and W-E section locations shown in figure 5 and 6.

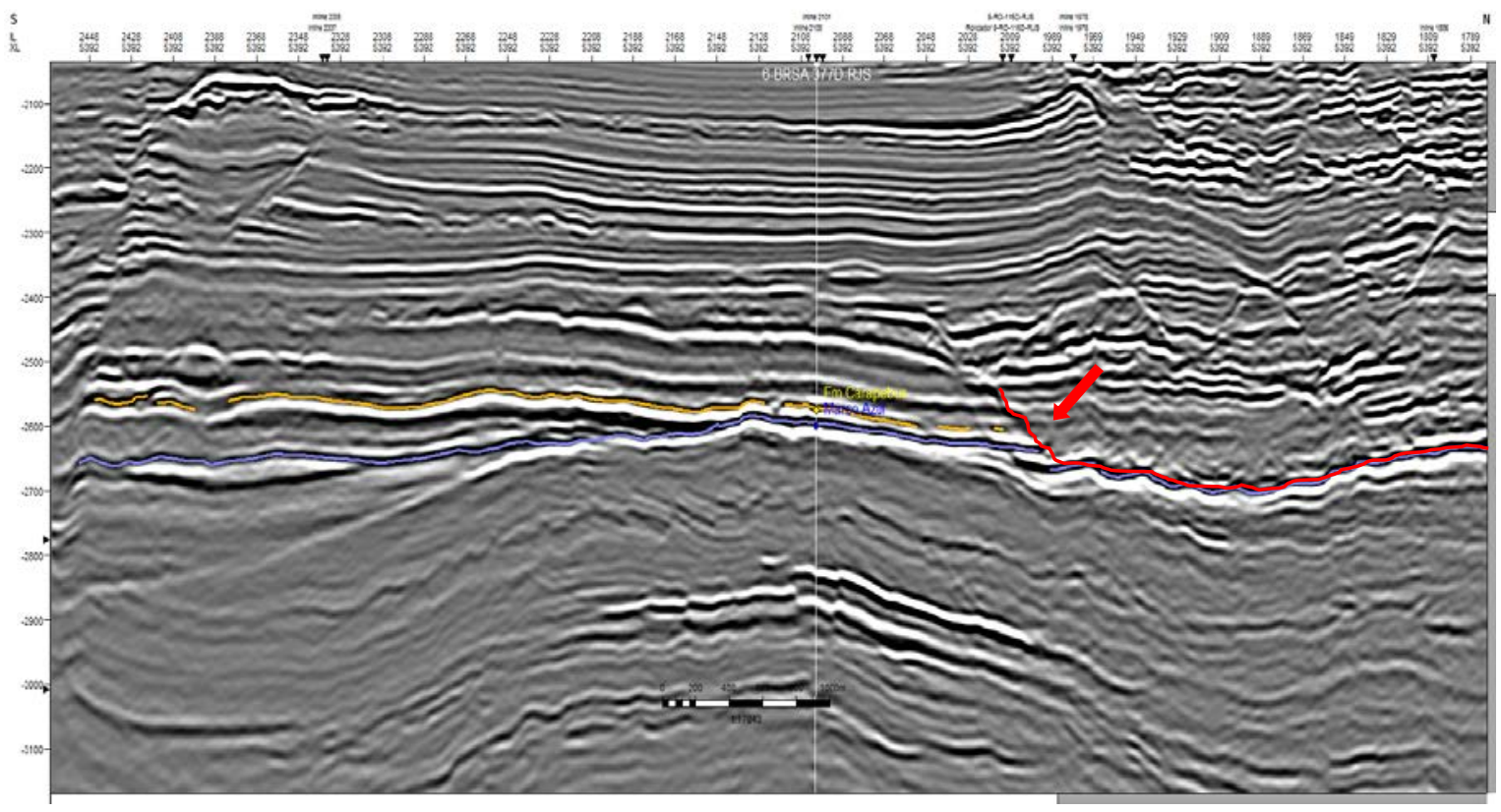

Figure 5: South to north seismic section showing the Blue Marker Carapebus sandstone horizons truncated by a pronounced erosive feature (red arrow) in the area. 


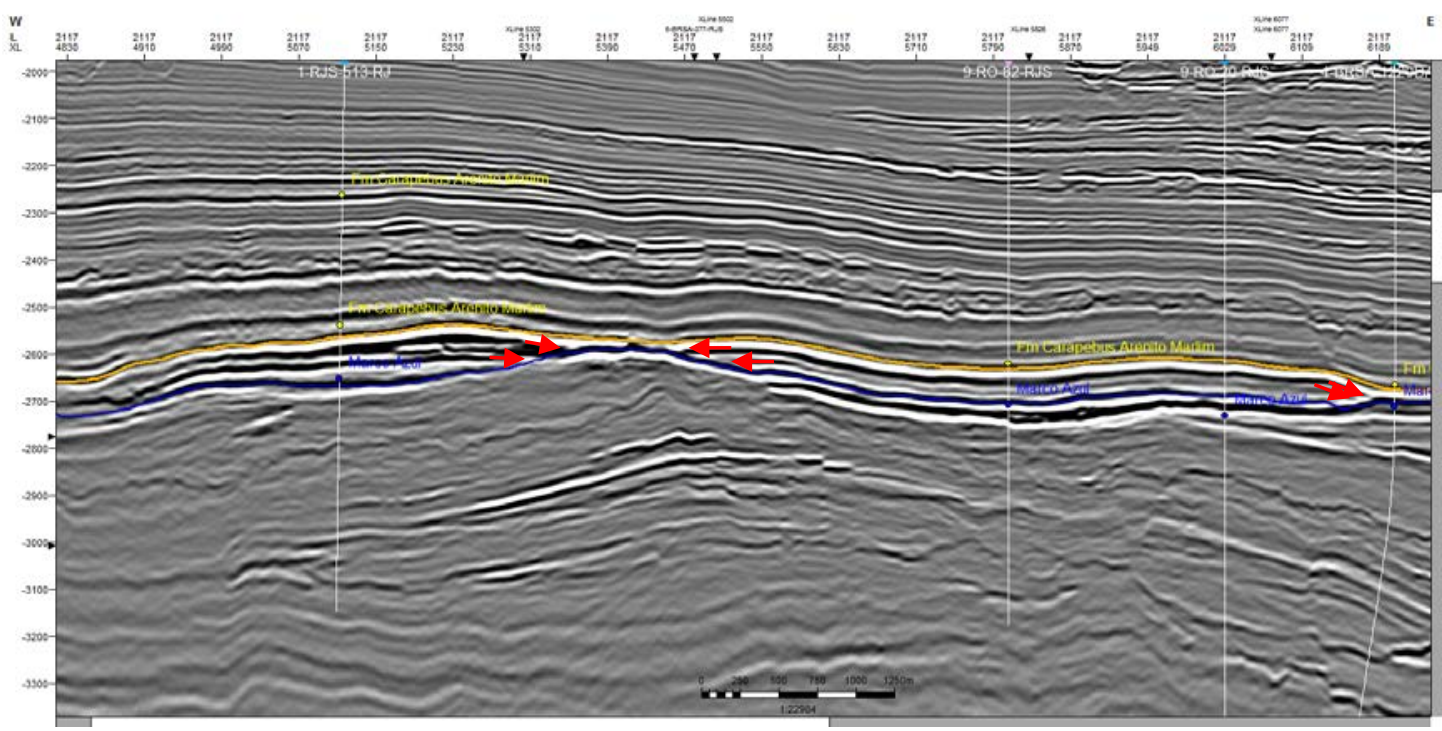

Figure 6: Inline W-E showing the interpretation of the Blue marker horizon (blue) with a strong high amplitude peak and the top of Carapebus sandstone (orange). Note the Carapebus sandstone layers pinch out against Blue mark surface (red arrows).

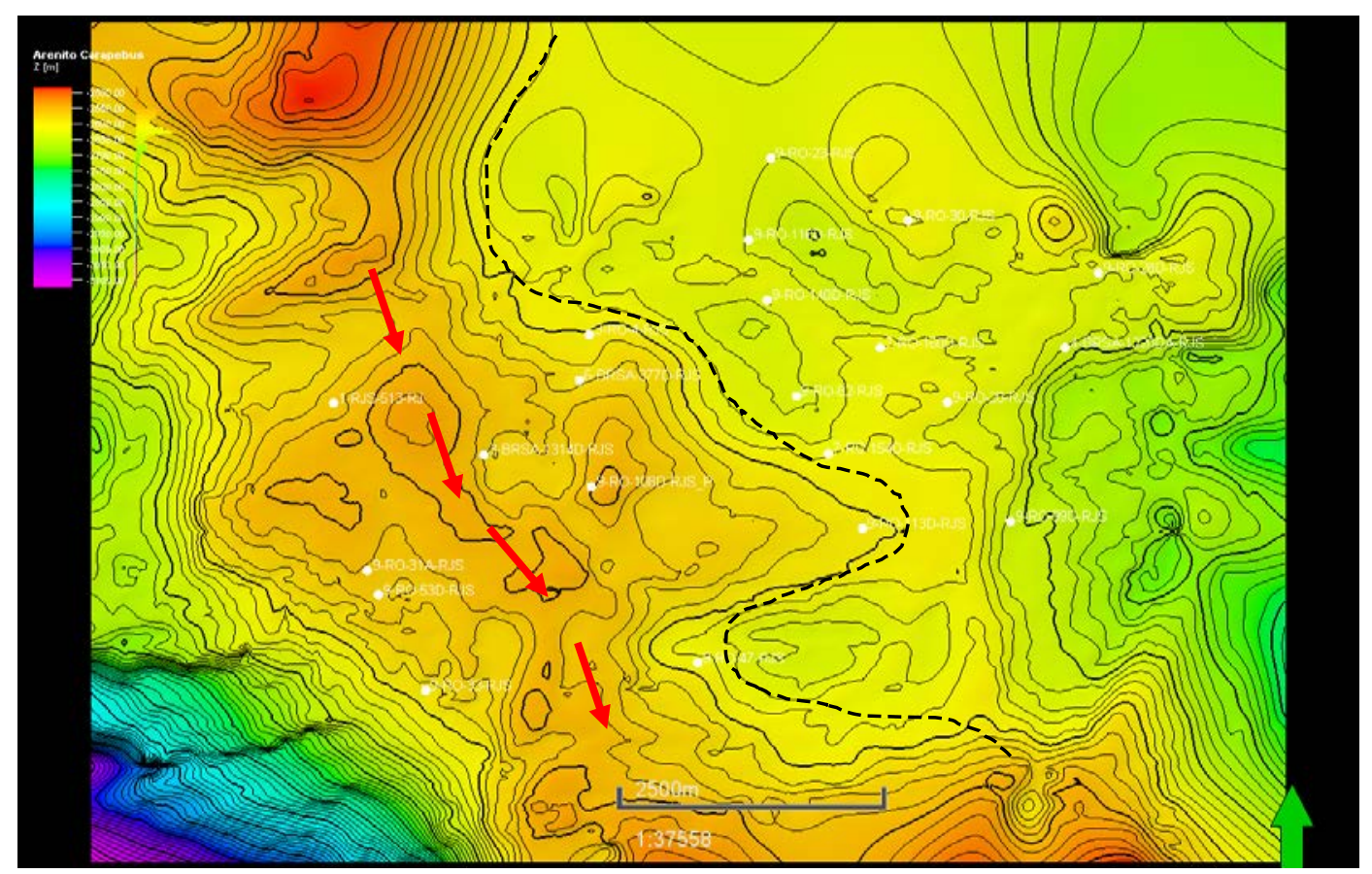

Figure 7: Top of Carapebus sandstones. The red arrows show the preferential depositional direction of the turbiditic sands. At the east side it is possible to notice an erosional feature that has eroded most of the sandstone layers (dash black line). Color bar shows Z values from -2500 (red) to -3300 (purple) meters. 


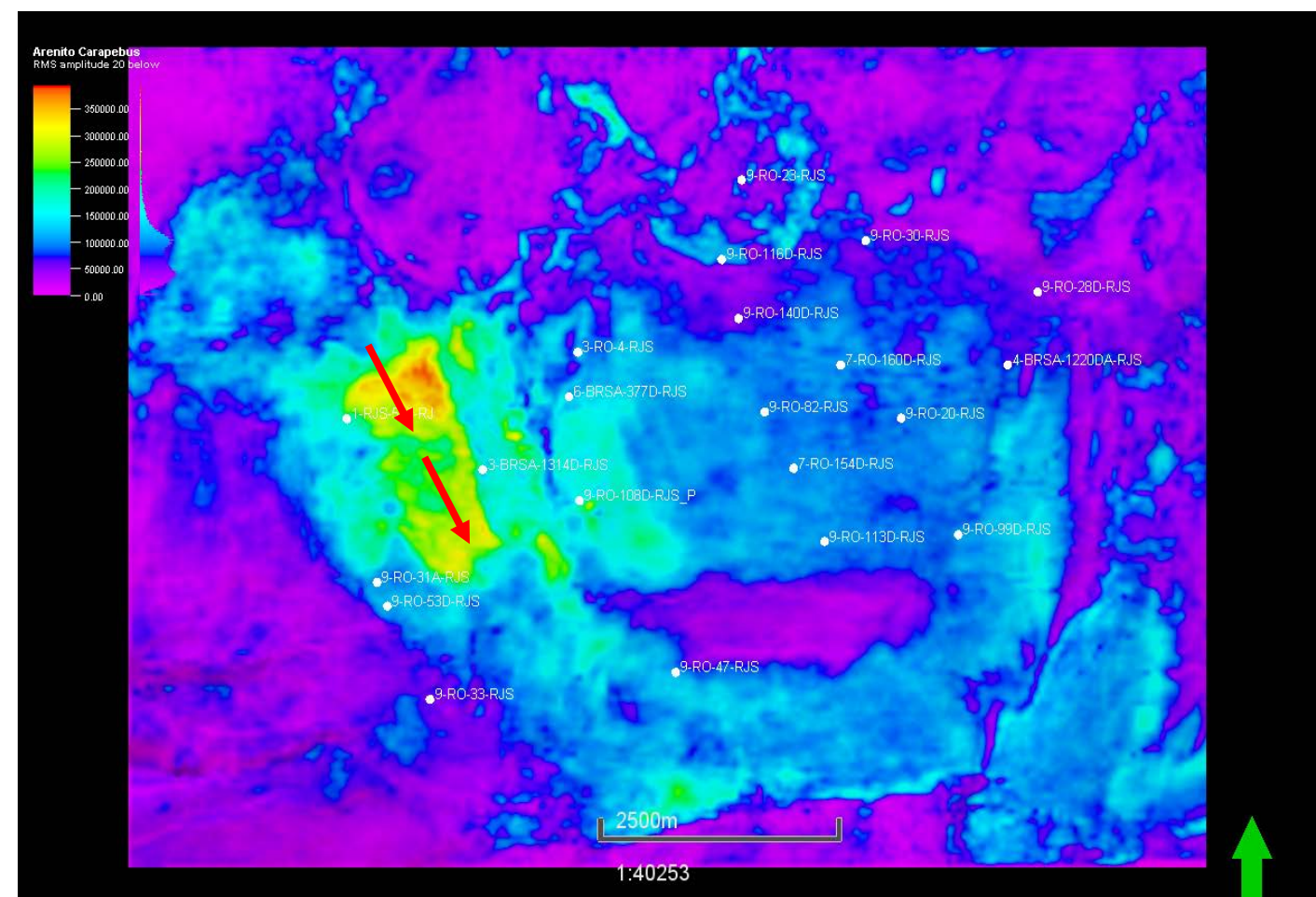

Figure 8: RMS amplitude map from Carapebus sandstone surface suggesting that the turbiditic current flow was from northwest to southwest. The red arrows show the turbidites flow direction. Color bar shows RMS amplitudes values from 350000 (red) to 0 (purple).

\section{References}

Peres, W.E. (1993). Shelf-Fed turbidite system model and its application to the Oligocene deposits of Campos basin, Brazil. AAPG Bulletin v.77, No 1. p 81101.

Mutti, E.; Cunha, R.S.; Bulhões, E.M.; Arienti, L.M.; Viana, A.R. (2014). Contourites and turbidities of the Brazilian Marginal Margins. AAPG ACE Houston.

Rangel, H. D.; Guimaraes, P. T.; Spadini, A. R. (2003).

Barracuda and Roncador Giant Fields, Deep Water Campos Basin, Brazil, in M,T,Halbouty,ed., Giant oil and gas fields of the decade 1990-1999, AAPG Memoir 78, p 123-137.

Suarez, C.R.; Souza, J.A.B.; Sarzenski, D.J.; Ida, M.; Elias, V.L.G. (2003). Reservoir characterization of Roncador, an ultra-deep giant field at Campos Basin, Brazil. SEG Technical Program Expanded Abstracts. p. 1462-1465.

Winter, W.R.; Jahnert, R.J.; França, A.B. (2007). Bacia de Campos. Boletim de Geociencias da Petrobras, Rio de Janeiro, v. 15, n. 2, p. 511-529, maio/nov. 